\title{
Powder Injection Molding - An Excellent Micromanufacturing Process to Produce Low-Cost Zirconia Dental Implants and Abutments
}

\author{
Lourenço $\mathrm{SH}^{* 1}$, Coelho $\mathrm{R}^{2}$ and Vieira $\mathrm{MT}^{2}$ \\ ${ }^{1}$ IPN - Instituto Pedro Nunes, coimbra, Portugal \\ ${ }^{2}$ CEMMPRE - Centre for Mechanical Engineering, Materials and Processes, Universidade de Coimbra, Portugal
}

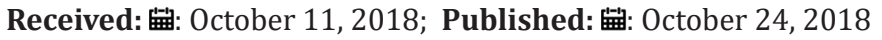

*Corresponding author: Lourenço SH, Instituto Pedro Nunes, CEMMPRE - Centre for Mechanical Engineering, Materials and Processes, Universidade de Coimbra, Portugal

Abstract

Micro Powder Injection Molding ( $\mu$ PIM) has being the elected process for large scale of near net shape of metal/ceramic parts with complex geometries. The present study demonstrates the feasibility of Yttrium-Stabilized Zirconia dental implants and abutments production by $\mu$ PIM leading to cheaper devices. The Coatings of nanocrystalline $\mathrm{Zr}_{x} \mathrm{O}_{y}$ an asset due the improvement of osseointegration.

\section{Introduction}

Nowadays the teeth loss is increasing reality which can affect, either physical and psychologically, all types of people. A high number of patients have one or more missing tooth and it is estimated that one in four Americans over the age of 74 have lost all their natural teeth. There are many options to replace missing teeths, but dental implants have become one of the most functional biomaterials to replace it over the last decades. The most used materials in dental implants are titanium and its alloys (historically) and zirconia (more recently) [1], since they have excellent biocompatibility with the hard tissues. Ceramic implants, mainly the stabilized zirconia implants, are gradually becoming an excellent option for implantologists, stimulating the interest of the biggest dental implant companies worldwide, due to factors such as biocompatibility [2] and non-release of metal ions, contrary to titanium implants. Besides, the white colour feature that prevents the development of greyish gums over time [3] and their excellent mechanical properties distinguish this biomaterial from the others [4]. Some companies are already producing and selling this type of implants, however in most of them, the implant and the abutment is one-piece. Besides, since the manufacturing process is subtractive, this kind of implants are extremely expensive.

\section{Powder Injection Molding}

The high cost associated to implants production, becomes a major hindrance for dental implants rehabilitation, being only available to more wealthy people. $\mu \mathrm{PIM}$ is a very promising near net shape technique, due to its advantages such as complex geometry, precision and large-scale production of implants with high performance, without requiring surface finishing steps [5]. The $\mu$ PIM process has five steps: raw material selection, mixing powder with binder for feedstock, injection moulding of feedstock into the mould with the desired shape (implant and abutment), debinding to remove the binder and sintering to give the required properties [6]. In order to select the yttria stabilized zirconia powder for feedstocks production is necessary to evaluate the $4 S^{\prime} \mathrm{S}$ (shape, particle size, particle size distribution and structure). It is also necessary to know the melting and degradation temperatures of the binder, to define the processing conditions for mixing and injection, as well as the binder removal cycle.

In feedstocks preparation is important to avoid a critical powder volume concentration (CPVC) in order to achieve an optimal mixing torque, to produce homogeneous feedstocks and consequently defect-free implants [7]. After an, homogeneous mixing, the feedstock is prepared for the injection moulding. Finally, the green parts - implant and abutment -, are extracted from the moulds, and then submitted to debinding and sintering, in order to obtain the final form. The debinding and sintering thermal cycles, were carried out in a high temperature oven under a controlled atmosphere of argon and hydrogen, to avoid a stoichiometric change of zirconia. The debinding cycle was based on binder thermal analysis (TGA= 
thermal gravimetric analyses) and the sintering conditions were carried out according to the selected powder.

\section{Surface Treatments}

Physical vapour deposition, like sputtering, allows the deposition of thin films, with a controlled structure, which allows the deposition of nanocrystalline coatings [8], [9]. The surface of implant is very important. being demonstrate in the literature that for titanium-based implants that surface roughness and nanocristallinity could be essential to osseointegration and bone-implant contact, promoting fast osteoblastic differentiation and reducing the recovery time of the patients [10], [11]. The application of zirconia (ZrO2) coatings in implants is the strategy used to improve osseointegration and biocompatibility [12], [13]. However, there are no references about studies of zirconia with different stoichiometry to be applied in medical dentistry. In order to contribute to the advancement of the scientific knowledge in this specific area, of the interface between the coating and the biologic material, were studied coatings with different $0 / \mathrm{Zr}$ ratios (ZrXOY) including ratio 2 [14]. In recent studies it's shown that mesenchymal stem cells isolated from the dental pulp (DPSCs) were successfully used, associated with the presence of a nanostructured coating, to promote osseointegration [15].

\section{Conclusion}

The $\mu \mathrm{PIM}$ technique is suitable to produce ceramic two-piece dental implants (implant and abutment). The surface of sintered dental implant is suitable for improving osteointegration with the combination of nanostructured coatings. The $\mu$ PIM process is an excellent strategy for manufacturing low-cost Yttria-Stabilized Zirconia Dental Implants with excellent biological and mechanical characteristics.

\section{Acknowledgement}

This article results in the project BePIM III through the program PT2020, COMPETE2020.

\section{References}

1. Osman RB, Swain MV (2015) A critical review of dental implant materials with an emphasis on titanium versus zirconia. Materials (Basel) 8(3): 932-958.

\section{ISSN: 2574-1241}

DOI: $10.26717 / B J S T R .2018 .10 .001944$

Lourenço SH. Biomed J Sci \& Tech Res

This work is licensed under Creative

Commons Attribution 4.0 License

Submission Link: https://biomedres.us/submit-manuscript.php
2. Nevins M, Camelo M, Nevins ML, Schupbach P, Kim DM (2011) Pilot clinical and histologic evaluations of a two-piece zirconia implant. Int J Periodontics Restorative Dent 31(2): 157-163.

3. Hisbergues M, Vendeville S, Vendeville P (2009) Zirconia: Established facts and perspectives for a biomaterial in dental implantology. J Biomed Mater Res Part B Appl Biomater 88(2): 519-529.

4. Sennerby L, Dasmah A, Larsson B, Iverhed M (2005) Bone tissue responses to surface-modified zirconia implants: a histomorphometric and removal torque study in the rabbit. Clin Implant Dent Relat Res 7 (suppl 1): S13-20.

5. Hong Kyun KIM, Kyung Mi WOO, Won Jun SHON, Jin Soo AHN, Seunghee CHA, et al. (2015) Comparison of peri-implant bone formation around injection-molded and machined surface zirconia implants in rabbit tibiae. Dent Mater J 34(4): 508-515.

6. Ferreita TJ, Vieira MT, Costa J (2016) Manufacturing Dental Implants using Powder Injection Molding. J Orthod Endod 2: 1.

7. FM Barreiros, MT Vieira, JM Castanho (2009) Met. Powder Rep 64: 18.

8. Surmenev R (2016) Radio Frequency Magnetron Sputter Deposition as a Tool for Surface Modification Implants Frequency Magnetron Sputter Deposition as a Tool for Surface Modification of Medical Implant. Intech 1-35.

9. Sunke V, Bukke GN, e Suda U (2018) Characterisation of nanostructured $\mathrm{ZrO}_{2}$ thin films formed by DC reactive magnetron sputtering. J Nanomedicine Res 7(2): 65-68.

10. Lai HC, Tsai HH, Hung KY, Feng HP (2015) Fabrication of hydroxyapatite targets in radio frequency sputtering for surface modification of titanium dental implants. J Intell Mater Syst Struct 26(9): 1050-1058.

11. Rasouli R, Barhoum A, Uludag H (2018) A review of nanostructured surfaces and materials for dental implants: Surface coating, patterning and functionalization for improved performance. Biomater Sci 6(6): 1312-1338.

12. Mandracci P, Mussano F, Rivolo P, e Carossa S (2016) Surface Treatments and Functional Coatings for Biocompatibility Improvement and Bacterial Adhesion Reduction in Dental Implantology. Coatings 6(1): 7.

13. Soon G, Pingguan Murphy B, Lai KW, Akbar SA (2016) Review of zirconiabased bioceramic: Surface modification and cellular response. Ceram Int 42(11): 12543-12555.

14. Coelho R (2018) Estudo de revestimentos de Zr-O para aplicações dentárias. Master degre thesis. Universidade de Coimbra.

15. Project I \& DT BePIM II - MICROdispositivos Biomédicos com capacidades osteointegradoras por $\mu$ PIM. Incentive Scheme: QREN - I \& D em Co-Promoção. 2015.

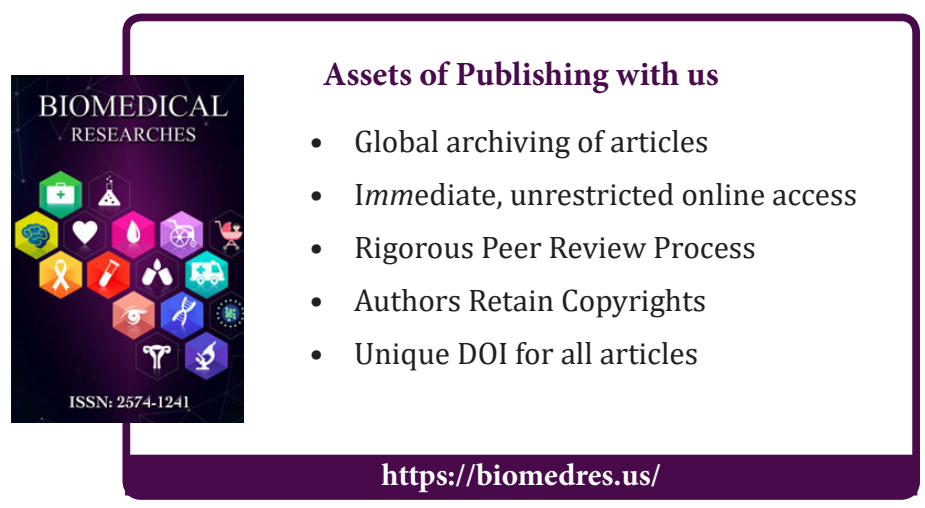

Cite this article: Lourenço SH, Coelho R, Vieira MT. Powder Injection Molding - An Excellent Micromanufacturing Process to Produce Low-Cost Zirconia Dental Implants and Abutments. Biomed J Sci\&Tech Res 10(3)-2018. BJSTR. MS.ID.001944. DOI: 10.26717/ BJSTR.2018.10.001944. 